\title{
Apps, activities and travel: an conceptual exploration based on activity theory
}

\author{
Dick Ettema ${ }^{1}$ (iD
}

Published online: 18 December 2017

(C) The Author(s) 2017. This article is an open access publication

\begin{abstract}
With the continuous advancement of (mobile) ICT devices and applications, their impact on travel, activities and time use becomes more diverse. This holds in particular for apps developed for mobile devices (smartphones). In this paper, we argue that the effect of ICT on travel and activities should be analysed at the level of a single specific device or application, rather than for broad classes of ICT devices. We propose activity theory as a framework to analyse the impact of smartphone apps on travel and activities. Activity theory describes how subjects apply tools (such as apps) to work on an object and achieve an outcome that is in line with the subject's motive. The application of the tool is embedded in an activity system which includes a community, formal and informal rules and in which a division of labour exists. We apply activity theory to analyse the effects of Whatsapp and travel feedback apps, based on existing literature about these apps. The analyses suggest that the activity systems of each app differ greatly in terms of object, motive, outcomes, community and rules, with implications for their use and impact. Both apps have an impact on travel, but differ with respect to whether this effect is intentional. For both apps contradictions in the activity system can be identified, which may give rise to further development of the activity system. These seem, however, to be largest for travel feedback apps. Based on our exploration, we argue that quantitative research on the impact of apps should be complemented by qualitative research based on activity theory. In particular, activity theory may help to gain a better understanding of underlying mechanism by which apps influence travel, to strengthen the theoretical underpinning and interpretation of the results of quantitative research and to explore changes in the development and use of apps and their impact on travel behaviour.
\end{abstract}

Keywords ICTs · Apps · Travel · Activity theory $\cdot$ Policy

Dick Ettema

d.f.ettema@uu.nl

1 Urban Futures Program, Faculty of Geosciences, Utrecht University, PO Box 80115,

3508 TC Utrecht, The Netherlands 


\section{Introduction}

Over the past decades many researchers have addressed the question what the rise of ICTs implies for travel behaviour (e.g. Mokhtarian 2002; Farag et al. 2003; Wang and Law 2007; Zhang et al. 2007). A typical characteristic of this field is that it is rapidly evolving in response to technological development (Lyons 2014). Whereas about a decade ago, most advanced ICT applications were based on communication using land lines (e.g. teleworking or teleshopping from home), nowadays large segments of the population own smartphones, which allow them to be connected to the internet anywhere and anytime, and apply a wide variety of software (apps). It goes without saying that as a result, the variety of ICT tools available to travellers has increased exponentially (Schwanen 2015).

The central tenet of this paper is that this dramatic development in the context of ICTs (and apps in particular) has profound bearing on the discussion about the impact of ICTs on travel, calling for complementary frameworks to the ones used to day. Whereas many studies to date tend to describe the effects of ICTs on travel in terms of the amount of increase/decrease of travel, the increasing diversity of ICT tools calls for more detailed analysis, which not only focuses on specific ICT tools rather than on broad types of ICTs, but also focuses in much more detail on the practices of using ICT tools and the contextual factors that influence their use and effect, as well as their further development. In the context of apps, Schwanen (2015) has argued that rather than focusing on the traveller as a decision maker, it is helpful to focus on the App as the object of investigation as it can be regarded as a more or less autonomous agent entangled in a web of relationships with humans and technological devices.

In agreement with this reasoning, this paper proposes an alternative approach to analysing the effect of apps on travel. In particular, we propose activity theory (AT) (Engeström 2014) as a framework for analyzing the effects of apps on travel behaviour. This paper aims to explore how AT can be used to further our understanding of the impact of apps on travel, and complement the existing approaches focusing at travellers' behaviour. To this end, we will use AT to systematically explore the mechanisms by which a number of different apps influence travel behaviour. We will assess the added value of AT as well as its limitations in the context of apps and travel.

The paper is organized as follows. "Existing approach to studying ICT and travel" section discusses existing approaches used to date to study the relationship between ICTs and travel. "Apps, activities and travel: a taxonomy" section then proposes a taxonomy of apps, which serves as a starting point for more detailed analyses using AT. "Activity theory" section introduces the principles of AT. "The effect of apps on activities and travel according to activity theory" section describes the application of AT to two smartphone apps (WhatsApp) and Travel Feedback apps. "Conclusions and discussion" section, finally, draws conclusions regarding the applicability of AT to the study of apps and their impact on travel, the mechanisms by which the two apps influence travel behaviour, and discusses possible avenues for further research.

\section{Existing approach to studying ICT and travel}

At the rise of ICT technology (such as the Internet), expectations were high that ICTs would offer a substitute for on-site activities and thereby strongly reduce travel (Salomon 1998). This hypothesis spurred a strand of research testing the effect that ICTs have on the 
amount of travel. Research in this realm acknowledged that substitution might not be the only effect (Mokhtarian and Tal 2013). Alternatively, ICTs may stimulate travel, for instance because time is saved that can be used for travel, allows travel time to be used more efficiently and allows social networks to be maintained over longer distances. Other options are that ICT modifies travel (e.g. choosing a different destination because of online information) or has no effect on travel at all (neutrality).

Empirical studies in this stream have mostly investigated the amount of travel (number of trips by purpose, travel distance by purpose) as a function of a rather general definition of ICT use. For instance, Wang and Law (2007) define ICT use as a binary variable indicating experience with any of a set of ICT tools, and investigate its effect on time use, travel time and number of trips. Zhang et al. (2007) investigate the effect of a set of ICT indicators (frequency of internet use, number of cell phones in the household) on VMT and the number of walking and total trips. In an overview article Mokhtarian (2009) reports that generation is the dominant effect of ICT on travel.

In addition, papers discussing the positive utility of travel (e.g. Mokhtarian et al. 2001) note that portable ICTs may influence travel decisions by making travel more productive [e.g. by working on a laptop (see Lyons et al. 2013)] or more pleasant and less boring (e.g. by gaming, reading or communicating: (see Lyons et al. 2013; Ettema et al. 2012). By making travel time more pleasant of productive, these ICTs may influence travellers' willingness to travel as well as travel time valuations.

Mokhtarian and Tal (2013) provide an overview of mechanisms increasing, decreasing or modifying travel which include a variety of ICT tools (phone, cell phone, email, web browsing etc.) applied for many different purposes. These examples imply that, while investigating the effect of general ICT indicators (e.g. frequency of Internet use) leads in itself to useful indications of ICT effects, they might be complemented by analyses looking more closely into the effects of specific ICT tools/applications, used for a specific purpose, since these might have specific outcomes. For instance, while using the Internet to buy groceries might have a travel reducing effect, browsing the Internet to find an outdoor activity on Sunday afternoon may have a travel generating effect. The need to focus in more detail on specific tools becomes even stronger in the context of multifaceted devices such as smartphones, which offer opportunities to call, text, browse the internet and use dedicated apps within one portable device, with each function and each app having potentially different implications for travel behaviour. This calls for an approach that distinguishes between specific ICT devices and tools, and the different practices of using them. In the remainder of the paper, we introduce $\mathrm{AT}$ as an alternative approach to studying the impact of ICTs, by focusing on smartphone apps as a specific category of ICTs.

\section{Apps, activities and travel: a taxonomy}

Given the diversity of apps currently available, apps should obviously not be regarded as a uniform category. In fact, Schwanen (2015) argues for studying their effects at the level of individual apps. In line with this view we carry out analyses of specific apps or groups of apps. However, to facilitate interpretation of the analyses, we developed a taxonomy of Apps, based on the intended impact of Apps on travel and activities, but acknowledging that Apps due to their footloose character may impact activities/travel at two levels: with respect to planning activities/travel and due to their use during activities/travel. This taxonomy (Table 1) of apps is based on the effect that they have on activities and travel, in 
a sense related to the classical classification of effects of ICTs in general in terms substitution, stimulation, modification or neutrality (Mokhtarian and Tal 2013). An important difference is, however, that apps, being installed on mobile devices that most carry with them 24/7, are footloose, and can be used anywhere (i.e. at home, on location and during travel). As a consequence, their impact on travel and activities is more diverse than of more traditional, stationary ICTs (such as a desktop computer with landline Internet connection).

A first category includes apps with functionalities not in a direct sense related to travel or physical out-of-home activities. Examples are apps offering access to online entertainment or games. In such cases, using the App is an activity in itself. Such apps may impact on out-of-home activities (and associated travel) by substituting for out-of-home activities (e.g. in-home gaming or entertainment instead of going to a cinema) or by competing for time. However, since apps are footloose, such entertainment based apps may influence travel and out-of-home activities also in a qualitative sense. Travelling while watching a movie or gaming may make travel more pleasant and less problematic, while using these apps during work, social and recreational activities fundamentally changes the value and character of these activities (Mokhtarian et al. 2001; Ettema et al. 2012; Lyons et al. 2013). The indirect effects of these qualitative changes on participation in out-ofhome activities and travel remains open for discussion and further research. For instance, using entertainment apps may make people decide to accept longer travel times in order to reach more remote destinations.

A second category of apps in some way facilitates the participation in activities and travel. Examples are apps for wayfinding and public transport trip planning, but also apps for finding (and ex ante evaluating) activity locations such as restaurants, entertainment centres, museums etc. On the longer term, in the context of repeated behaviours, we can also regard travel and activity feedback apps as falling in this category. For instance, apps providing feedback on daily levels of physical activity (step counters), may influence travel mode choice (active vs. passive) or invoke activities with more physical activity. The direct effect on activity participation and travel is straightforward, in the sense that information about travel and activity conditions, as well as feedback on travel and activities, may

Table 1 Taxonomy of apps and effects on travel and activities

\begin{tabular}{llll}
\hline Category & Examples & $\begin{array}{l}\text { Effects on activities/travel } \\
\text { decisions }\end{array}$ & $\begin{array}{c}\text { Effect during travel/ } \\
\text { activities }\end{array}$ \\
\hline $\begin{array}{c}\text { Not related to } \\
\text { travel or out-of- } \\
\text { home activities }\end{array}$ & Games, entertainment, news & $\begin{array}{c}\text { Substitution, competition for } \\
\text { time }\end{array}$ & $\begin{array}{c}\text { Change of travel/ } \\
\text { activity experience }\end{array}$ \\
$\begin{array}{c}\text { Supporting travel } \\
\text { and activity } \\
\text { planning }\end{array}$ & $\begin{array}{c}\text { Short term (daily): Travel } \\
\text { planning apps, apps for } \\
\text { finding destinations } \\
\text { Longer term: travel and } \\
\text { activity feedback apps } \\
\text { Apps for banking and on-line } \\
\text { shopping }\end{array}$ & $\begin{array}{c}\text { Generate activities/trips, } \\
\text { moderate trips }\end{array}$ & $\begin{array}{c}\text { Moderate travel and activities } \\
\text { Supressing physical activities } \\
\text { activities }\end{array}$ \\
$\begin{array}{c}\text { Supporting virtual trips, saving time for } \\
\text { other activities }\end{array}$ & $\begin{array}{c}\text { Change of travel/ } \\
\text { activity experience }\end{array}$ \\
$\begin{array}{c}\text { Communication } \\
\text { photo, film) }\end{array}$ & $\begin{array}{c}\text { Skype, Whatsapp, Instagram, } \\
\text { Snapchat }\end{array}$ & $\begin{array}{c}\text { Coordination: generation, } \\
\text { modification or substitution }\end{array}$ & $\begin{array}{c}\text { Change of travel/ } \\
\text { activity experience, } \\
\text { connected presence }\end{array}$ \\
\hline
\end{tabular}


influence activity choice, mode choice and location choice. To our knowledge, however, limited knowledge has been accumulated about the quantitative effect. Apps from this category may have an additional effect on activities and travel as they (like any App) can be used during activities and travel. For instance, one may look for the best bus connection to the final destination while making a train ride, or find the best restaurant while attending a meeting. Such App use may change the character of and attention given to travel and activities and affect their pleasantness and value. Again, such effects remain open for further research.

A third category of apps has a direct impact on activities and travel by substituting for activities on location. Common examples include banking or online shopping via a smartphone App. In line with the first hypotheses about the effect of ICTs on travel, the effect may be that trips to physical locations are suppressed. However, it is likely that the time saved by not visiting a physical facility, is used for additional trips and activities, that would not be made otherwise. Again, such apps can be used anywhere and anytime, including during travel and other activities, which may change the character of travel and out-of-home activities, affecting how they are appreciated.

A final category of apps provide their users with tools for communication with other App users. Such communication includes voice, photo, video and instant messaging. While such communication may include issues also addressed by other App categories (entertainment, information gathering), the set of communication apps available on current smartphone provides a unique situation of 'connected presence' (Licoppe and Smoreda 2006), implying that everyone in one's social network can be contacted anywhere and anytime at almost no costs, to communicate about practical, important and trivial issues by a variety of modes. Communication may also invoke face-to-face contacts, leading to outof-home activities and travel. Obviously, this state of connected presence extends to travel and out-of-home activities, with impact on how time is spent during travel and activities and how they are experienced.

The taxonomy bears implications for how the relationship between apps, travel and activities is conceptualized theoretically. Traditional travel theory suggests that activities and their associated travel are invoked by specific motives or needs. Apps may interfere with this process in multiple ways. In relation to motives and needs, a general need (e.g. for entertainment) may not only lead to an activity in a specific facility (e.g. a cinema), but also to using an App to fulfil the need (e.g. gaming). However, App use may also invoke a need leading to activity/travel, for instance if an App provides information about real life places worth a visit (e.g. an advertisement for an event via social media). Apps may facilitate travel and activities by supporting planning and logistics as discussed before. Furthermore, in line with studies of positive utility of travel time, apps may change the travel/activity experience if they are used during travel and activities, with implications for future activity and travel engagement. Finally, apps may be used to obtain objective feedback about one's travel or activity behaviour.

\section{Activity theory}

Activity theory (AT) dates back to the work of Soviet psychologists and Marxist philosophers (see Vygotsky 1978), and was introduced to the western world in the 1980s by the Finnish psychologist Engeström (2014). AT aims at describing and understanding individuals' mental processes (such as decision making) in relation to their physical 
environment by analysing practices in their real life context. The central notion is that consciousness (including decision making, classification and remembering) is not disconnected from everyday practice, but intrinsically tied to it. According to AT, our mental processes are determined by our daily practices and vice versa. Hence, if we are to understand human behaviour, we need to study it, according to AT, in connection with the tools associated with that behaviour, since these not only provide the means for engaging in the behaviour, but will also influence peoples' attitudes and decision making preceding the behaviour. Based on these principles, AT has been applied frequently to the fields of for instance ICT supported learning (e.g. Lim and Hang 2003) and human computer interfaces (HCI) (e.g. Nardi 1996a, b). In the remainder of this section we will further introduce AT.

\section{Activity systems}

AT describes activities in a very general sense as a subject (a person) working on an object, mediated by tools, and aimed at a certain outcome. In addition, the activity is embedded in a social context, and is subject to certain rules. The activity together with the structure in which it is embedded is called the activity system (see Fig. 1). The subject is the person acting on the world, in our case the traveller using a smartphone App. The activity implies that the subject uses a tool to bring about a change to an object. Tools can be mental (e.g. using arithmetic to solve a maths problem), physical (e.g. a hammer) or virtual (e.g. software). Hasan and Kazlauskas (2014) distinguish between primary tools (physical), secondary tools (language, ideas, models) or tertiary (communities, contexts or environments). An important notion in AT is that tools mediate but are also mediated by their surroundings (Fjeld et al. 2002). That is, the tool allows the user to materialize internal mental activity into material artefacts (exteriorization). In reverse, contact with the physical surroundings and the social context stimulate mental activity (internalization), for instance handling increasingly more abstract concepts and objects.

Tools are used to work on an object, that is changed in order to achieve an intended outcome. Like tools, an object can be material (e.g. a nail being hammered) or non-tangible (e.g. a Word document being modified, a bank account that is increased or a public opinion being influenced). The application of the tool to an object results in an outcome, which, if the activity system works right, was intended by the subject. AT supposes that activities are undertaken with a certain motive, which is to satisfy a need (Kaptelinin and Nardi 2006). However, activities may in AT have multiple motives. For instance, a cyclist cycling to work may do so to address various motives, such as getting to work timely, getting exercise and enjoying the landscape, which relate to different needs such as self-realisation,

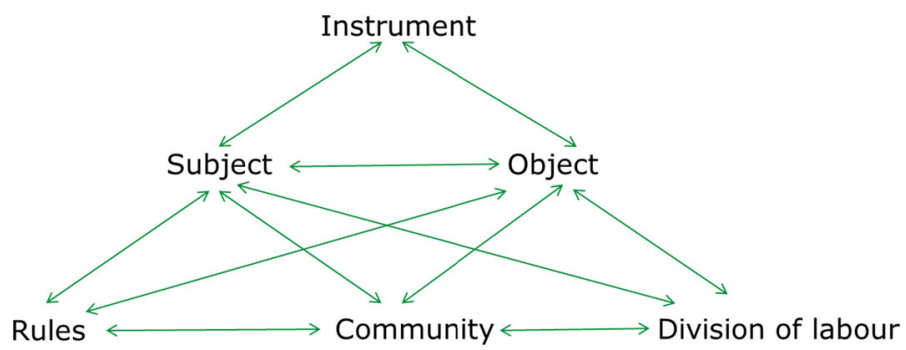

Fig. 1 Activity system (after Engestrom 1999) 
restoration and achievement. According to Kaptelinin and Nardi (2006), the combination of motives determines the way the activity is carried out. For instance, if the only motive of a traveller is to get to work on time, a trip by car may be the preferred option. However, if maintaining health and fitness is another motive, the car is not an appropriate tool, and the bicycle offers better opportunities for satisfying the underlying needs. The differences in needs and motives between people in relation to the same 'objective' activity (in this case commuting) implies that objects in AT are defined at an individual level and in different ways (Hasan and Kazluaskas 2014).

AT furthermore holds that activities are embedded in a social context, which involves rules, a community and division of labour. The community are other individuals, involved in activities that are related, but not identical to the activity carried out by the subject. The community may consist for instance of colleagues in a company with which one cooperates. The involvement of other people implies that activity systems are multi-voiced (Engestrom 1999): different people involved will have different interests, opinions and traditions, so that the object addressed in the activity system has different meanings for different involved people. This may be a source of tension, but also a driver of change in the activity system, leading to modifications and improvements. These different viewpoints by different parties in the activity system are related to the division of labour within the system. For instance, in a school teachers and pupils both work on the teaching activity (Lim and Hang 2003), but with clearly different tasks and responsibilities and interests.

Finally, the activity system is subject to rules. Rules can be more or less formal, and define how the subject should behave within the community. For instance, in the context of travel, formal rules could pertain to where and when travel modes are allowed to use (highways, cycling paths, pedestrian areas, use of an off-peak travel pass for public transport). Implicit rules are related to norms in the community regarding what is appropriate behaviour, such as using bicycle or public transport not being in accordance with a manager's status.

\section{Activity systems under development}

A central notion of AT (Engestrom 1999) is that activity systems are not constant and go through an ongoing process of transformation. One reason, as mentioned before, is the multi-voicedness of activity systems, relating to the multiple actors involved in the community of most activity systems. In this respect, it is helpful to realize that the actors involved in the activity system of the subject, are also subjects themselves in their own activity systems. Hence, we can conceptualize the social context of activities as a network of interlinked activity systems, each with their own objects and goals and having different perspectives, which may lead to tension, dialogue, negotiation and innovation.

A second reason is that activity systems are open systems, which may adopt new elements from outside. These include new technologies or new actors, which cause changes in the functioning of the activity system and may lead to tensions, due to different interests and viewpoints. For example, Lim and Hang (2003) describe how the introduction of ICT facilities in classrooms in Singapore lead to contradictions between optimizing flexible ICT learning facilities to their full extent, and sticking to a quite rigid classical form of education. In the end, the system was adjusted by allowing pupils to take more responsibility about their ICT supported learning activities, and shifting teachers' role partly from frontal lecturing to coaching.

Contradictions are seen as fundamental in evolving activity systems, since they trigger changes by negotiating task and responsibilities, changed practices or improved tools. A 
consequence of activity systems as being in an ongoing state of transition is their historicity. This implies that the functioning of activity systems is path dependent, and should be understood in the context of their past states and subsequent changes. Only in this way can practices and their embeddedness in systems of rules and labour division be understood. In addition, historicity implies that activities and the use of tools are influenced by cultures, which can in term be seen as the outcome of the accumulation and transmission of social knowledge through the activities.

\section{Applications of AT}

While AT can potentially be applied to the study of any tool assisted activity, many applications (and also relevant for the current paper) concern Human Computer Interface studies. From a theoretical point of view Nardi (1996a, b) discusses the principles of AT and how AT can be applied to study HCI in specific contexts. She emphasizes that objects in the context of HCI are not static and may differ between users. She also notes that an activity in the context of HCI may involve both actions (i.e. consciously carried out, such as using software for the first time) and operations (automatically carried out, such as typing a word). The key notion, however, is that activities are mediated by ICTs and that in fact the activity and the ICT should be regarded as mutually dependent and unified. Examples of applications include (as described above) the use of AT to study the use of computers as a learning tool in class rooms in Singapore (Lim and Hang 2003), to design adaptive e-learning systems (Peña-Ayala et al. 2014) and the design of groupware (Fjeld et al. 2002). Carvalho et al. (2015) apply AT to develop a conceptual model of the use of serious games. In particular they acknowledge that the activity of playing a serious game may have different motives for different individuals, partly depending on their role (player or instructor) leading to different actions and implications for game design. Given that smartphone apps can be regarded as software running on a particular type of computer (handheld mobile devices), this paper proposes that AT provides a promising tool to investigate the impact of smartphone apps on activities and travel, doing right to the variety of apps and users with their differences in objects, rules and communities, giving rise to contradiction and development.

\section{The effect of apps on activities and travel according to activity theory}

Kwan (2007) argues that to understand the effects of ICTs on travel and activities, it is important to acknowledge that ICTs relieve spatio-temporal constraints and the role of distance on which traditional models of mobility behaviour (such as gravity models, four stage models or time geography) are based. In particular, the point based representation in these models of people and social networks is limiting when investigating the effects of ICTs on activities and travel. Kwan argues that alternative metaphors may help us to understand the effect of ICTs on travel. In this section we elaborate on the application of AT as such a metaphor to better understand the working and implications of apps. A particular feature of AT is that it is not based on notions of distance or proximity, and that it is not limited to activities and tools taking place in physical locations. As discussed, tools and objects in AT may be physical, mental or virtual. Therefore, AT is a potentially promising theory to study ICTs (here apps), acknowledging both the physical, mental and virtual levels in which apps work out. 
The taxonomy outlined in "Apps, activities and travel: a taxonomy" section already provided first indications of the potential effects of smartphone apps. However, their exact effects depend on their use as tools as part of activities by subjects while working on a specific object, as suggested by AT. It should be noted that also within (sub)classes of this taxonomy, apps may have different effects, as their functionalities, but also their rules and communities and the motives of their use may differ. Below we present such specific analyses based on AT for apps from specific subclasses: a communication by instant messaging App (Whatsapp) and travel related (travel feedback) apps. As specific instances of their subclass, they illustrate how travel related and other effects of apps can be analysed using AT.

\section{Whatsapp}

Whatsapp is an instant messaging app, which can be downloaded on smartphone free of charge. The basic working is such that once access to Internet is available, users may send messages to each other free of charge, which appear directly on the smartphone screen, and can be replied to easily by typing text directly in a data window and send it. In addition, photo, video and audio clips can be easily attached and sent. Whatsapp is regarded as a significant improvement over earlier messaging system such as SMS, in that acquisition and use are free, and different media (text, photo, video and audio) are integrated and easy to use. Another improvement is that Whatsapp allows for the specification of groups, allowing each group member to send messages simultaneously to all other group members. Whatsapp has been adopted by large segments of the population (e.g. 9.8 million users on a total population of 17.0 million in the Netherlands in 2016) allowing it to be used easily for communication with friends, club members, colleagues etc. In the remainder of this section, we will discuss the activity system in which Whatsapp serves as a tool, followed by an analysis of potential travel effects.

\section{Object and practices}

Subjects use Whatsapp to work on an object. One may be tempted to define the object of Whatsapp as information being transferred from sender to receiver. However, the information delivered by Whatsapp is only a means to fulfil a more fundamental need: the fostering of friendship relationships. O'Hara et al. (2014) specifically describe Whatsapp as a tool for 'doing friendship'. Users of Whatsapp describe the information exchanged as falling into different categories. There is exchange of practical information, such as notifications of being late, coordination of gatherings, instigating joint activities and checking others' well-being and wherabouts, but also an exchange of gossip and tosh, jokes and mockery and discussion of philosophical issues. In short, any sort of communication in friendship relations appears to have a Whatsapp equivalent. The studies we reviewed suggest that Whatsapp offers the opportunity to have an ongoing conversation with others, which can be simultaneous (two users directly responding to each other) or paused. Users defined Whatsapp as being more 'conversational' and fluid than for instance SMS (Church and de Oliveira 2013). Although the literature is not fully conclusive, Whatsapp seems to be used in a complementary fashion to communicate with people that are also frequently met face to face. Whatsapp then offers a form of connected presence, i.e. being together with close ones almost continually in a virtual way (Licoppe and Smoreda 2006). Hence, the main object of Whatsapp appears to be the maintenance of social ties, rather than 
fulfilling travel related needs. As we will see, however, differences in the way friendship is done brought about by Whatsapp, may have implications for daily travel.

\section{Community, labour division and rules}

Using Whatsapp for doing friendship is embedded in a community of other Whatsapp users, with whom messages are exchanged, but probably also a community of non-users, such as friends and family members not using the App. Regarding the community of users, Whatsapp creates an in principal egalitarian environment, where all users have similar options to exchange information. As a consequence, there are no formal rules to the use of Whatsapp. The community may however apply informal rules, related to content, amount and timing of messages (O'Hara et al. 2014). In addition, receiving Whatsapp messages may raise expectations to respond to them within certain time limits. This is due to the possibility offered by Whatsapp to see if someone else is online, and whether she has already received and read your Whatsapp message. Also, expectations may be developed related to courtesies such as notifying late arrival or change of plans to Whatsapp relations.

\section{Development and contradiction}

AT claims that practices are (re)developed in connection to changes in the activity system. The literature suggests that this is also the case for WA. The availability of an instant messaging app has changed expectations of how friendship is done, and added a layer of connected presence with close ones, serving both practical and emotional/affective purposes. People's creative and adaptive capacities have, with the increasing availability of social network applications such as Facebook, Twitter, Whatsapp etc., led to a form of channel blending, where the most convenient or appropriate channel is chosen for a specific purpose. For instance O'Hara et al. (2014) report that whereas a group in Whatsapp served well for informal exchange of information and gossip, a more formal invitation for a party extending to the partners of the group members, was better distributed via Facebook.

However, the literature also reports contradictions that arise when using WA. In some cases, users had different expectations about the content of messages, such as using Whatsapp to invite someone for a romantic date. Also the amount of messages sent, especially in Whatsapp groups may easily accrue, especially when being offline for some time, leading to annoyance and stress. Also the pressure experienced by some to quickly respond to an incoming measure, due to the notification of a message being read sent to the sender, can be considered a contradiction. The literature is indecisive how such contradictions may influence the activity system of doing friendship in the future. One response seems to be to use unintended loopholes (e.g. reading the message in the push message rather than in the App), protecting oneself by staying away from the smartphone for a while, or withdrawing from a group.

Other contradictions may arise if the community in the activity system also includes non-WA users (or those being physically present when one is using WA). For instance, when meeting face to face with friends and family, exchanging Whatsapp messages with others at the same time impacts on (and likely disturbs) the communication with face-toface company. When in the company of strangers, face-to-face company may be affected by others using smartphones. Although using Whatsapp may not be as intrusive as talking on the phone in public places (Bissell 2010) it likely impacts the atmosphere to some extent, ad can be experienced as annoying or not desirable. 


\section{Travel (and activity) implications}

In the context of Whatsapp being part of an activity system for 'doing friendship', the literature suggests that using Whatsapp may have implications for travel, even if accommodating or coordinating travel is not the direct outcome that users seem to envision. At the most general level, we may conclude that Whatsapp has to some extent changed the practices of doing friendship, and thus impacts on the ties established and maintained with other individuals. As a considerable literature (e.g. Carrasco and Miller 2009) suggests that a direct relationship exists between size and content of one's social network and the amount of travel one does, and that the type of relationships matters (strong ties vs. weak ties), we hypothesize that social ties supported by Whatsapp might invoke different travel behaviour than those not supported by WA.

The reasons for this may vary. At the most fundamental level, Whatsapp supported ties might be stronger, because one knows more about the 'alter' (such as activities undertaken and daily experiences), which may trigger the need to meet in person and talk. The literature suggests indeed that Whatsapp is mostly used as an additional contact mode with people living on close distance, with which one regularly meets (O'Hara et al. 2014). On the other hand, if Whatsapp contacts are mostly frequently met face-to-face, the travel impact of such an effect is likely not very large.

From a more practical angle, the literature suggests that Whatsapp is used for microcoordination of activities, such as instigating spontaneous gatherings with others who happen to be in the vicinity, or changing destinations last minute. Especially the group function of Whatsapp allows for efficient last minute coordination and planning, suggesting that this may lead to social activities (and associated travel) that might not have happened otherwise. In addition, the literature suggests that Whatsapp is used to coordinate household tasks such that others do not have to travel (e.g. checking whether a household member needs something from a store where you are).

Other implications of Whatsapp for travel concern the experiential side of it, and can be understood from the activity system outlined above. For instance, in the context of doing friendship, Whatsapp is used not only to coordinate joint activities, but also to evaluate and relive them afterwards. While this may serve to strengthen the friendship tie in general, it also potentially influences the memory of a joint activity, thereby changing the culture in the community (e.g. a Whatsapp group) toward the activity and affecting its future occurrence (including the associated travel).

On the other hand, using Whatsapp during travel may influence how travel is experienced. According to Lyons et al. (2013) about one third of train passengers send text messages during travel (although unknown to what extent Whatsapp is used). Based on data collected in 2010, Ettema et al. (2012) found that use of ICT in public transport lead to worse travel experiences, which they attributed to the fact that they were used to kill time and fight boredom. However, since Whatsapp is of a more conversational character than SMS and provides a stronger sense of connected presence, Whatsapp use may not have this negative effect and even makes travelling more pleasant. An additional way in which it changes the travel experience is through the ability to almost instantly share photo or video images of what one encounters during travel (Wang et al. 2012). This option to share experiences directly with other may intensify travel experiences, both for the good and for the bad. However, all potential experiential outcomes are deliberately stated as hypotheses, since empirical work in this area is lacking. 


\section{Travel feedback apps}

Over the past decade various apps have been developed, aimed at reducing peoples' car use, by providing them feedback about their travel behaviour. These apps build on a tradition of studies regarding travel feedback, where travellers receive detailed information about their travel options and about the consequences of their current travel behaviour (e.g. Fujii and Taniguchi 2006). Such so called 'soft policies' (Richter et al. 2011) build on principles from theories such as the Theory of Planned Behaviour, and have demonstrated that both one's belief about the consequences of travel outcomes, social approval and perceived behavioural control influence a change in travel behaviour. Typically, traditional travel feedback studies have been found to be effective in reducing car use more than $10 \%$ (Richter et al. 2011).

Various scholars have aimed to improve the efficiency of such programme with the use of apps. Since smartphone include a variety of sensors that can be used to monitor individuals' travel behaviour, dedicated apps, that communicate with servers and algorithms in a back office, have been developed that monitor individuals' travel behaviour and provide feedback on it, with the intention to change it in more sustainable directions. Such travel feedback apps also draw on gamification principles (Wells et al. 2014). For instance, travellers can earn rewards when displaying the desired behaviour, which can be only virtual but also monetary or in kind. In addition, travel feedback apps often use social comparison mechanisms. Travellers may be compared to the average of the other participants (sometimes called the community), or to self-set goals. In this section, we discuss the activity system based on a number of reported studies of travel feedback apps (Gabrielli and Maimone 2013; Wells et al. 2014; Broll et al. 2012; Meloni and di Teulada 2015; Jariyasunant et al. 2015; Brazil et al. 2013).

\section{Subjects, objects, motives and practices}

In terms of AT, the definition of subjects applying travel feedback App depends on how the AS is defined. One option is to define the activity system in terms of the traveller as the subject, who uses the tool (Travel feedback App) to adjust and optimize her travel behaviour under specific conditions, and based on information provided. The object and motive in this case is, according to the literature, somewhat ambiguous. On the one hand, it can be defined as a sustainable and healthy travel pattern, as the travel feedback apps are aimed at promoting environmentally friendly travel modes and stimulating PA. On the other hand, it includes an element of maximizing the non-travel related output, such as virtual, material or monetary rewards, or social status. In this sense, travel behaviour becomes a polymotivational behaviour. The motivations of travel feedback App users are to our knowledge however not discussed in the literature. Based on the existing literature, fairly little is known regarding the practice of using travel feedback apps by travellers. The literature describes some outcomes of using travel feedback apps, but almost nothing about their daily use, such as how often, and at what times they are used, and which features of the apps and associated websites are used.

\section{Community, labour division and rules}

From the above, it follows that the community, labour division and rules can defined in different ways. From the perspective of the traveller as the subject, the community includes 
the consortium launching the App, which communicates with the traveller and determines the 'rules of the game' such as the behaviours that are valued/rewarded and the type and size of the rewards. In addition, the community includes other participants in the programme. These serve mainly as a benchmark against which the traveller's behaviour is compared, or as the audience of announcements of achievement or status of the traveller. Occasionally, if travellers in the programme know each other (e.g. if multiple participants are colleagues), the social comparison included in the feedback program may have extra impact, as comparison to familiar people likely weighs more than a comparison to anonymous participants. The rules in this AS are defined by the consortium, and define what travel behaviour is rewarded/appreciated, the type and size of rewards, what feedback is delivered to the participant. Rules likely also include carrying one's smartphone during travel with the app operational for tracking purposes, as well as the obligation to specify information by filling out surveys, especially if the travel feedback project is carried out for research purposes.

\section{Contradictions and developments}

AT suggests that activity systems may be part of networks of activity systems, that have different motives, which may lead to tensions and contradictions. The literature we reviewed suggests that this may indeed be the case when applying travel feedback apps. For instance, Wells et al. (2014) report the possibility that if rewards are not correctly specified, participants may maximize their rewards without necessarily displaying the preferable behaviour. This seems to be based on the (potential) difference in motives between the organizing consortium (reducing car travel) and participants (maximizing material or monetary gain). It should be noted that participants in travel feedback programmes are not necessarily (only) in it for the money. While the studies on travel feedback apps we reviewed did not explicitly discuss participants' motivations for participating, an earlier study on travel feedback and reward (Ben-Elia and Ettema 2009) suggested that one third did not mention financial motives for participation, and many mentioned additional motivations such as curiosity and societal concern.

This contradiction may also have implications for the long term effects of travel feedback App programmes. If participants are involved with the motive of maximizing material or financial benefits, they are likely to not maintain the desired behaviour once the reward ends. This effect was for instance clearly shown in the Netherlands Spitsmijden project (Ben-Elia and Ettema 2011). Not all apps involve a monetary of material reward and they have mostly been applied in shorter lasting test cases. This raises the question to what extent travellers will remain sufficiently motivated to use the App and maintain their (possibly) changed behaviour. One App gives users abstract points for using basic functionalities of the App, but it is unclear whether this aligns with users motives to use the app.

Other contradictions, mainly stemming from different motives of consortium and travellers, are mentioned. Gabrielli and Maimone (2013) mention that participants may find the challenges posed as exaggerated, leading to lowered motivation in trying to meet them. More generally, being able to reconcile travel behaviour changes with one's daily activities and activities seems to be a prerequisite for successful outcomes of travel demand management programmes. Ben-Elia and Ettema (2009) found that in a programme for peak hour avoidance, fixed work hours and household obligations were major reasons for not participating in such a programme. Others (Gabrielli and Maimone 2013) reported that they did not like to display their achievements on social media. In general, privacy 
concerns seem to be a major issue for people when deciding to enrol in a programme where their whereabouts are tracked. Hence, the factors that maximize behavioural change according to various behavioural theories (goal setting, social comparison) are not uniformly appreciated by participants, and may potentially lead to drop out or not signing up.

Finally, a contradiction was reported between the consortium's aim to change participants' behaviour but also their attitudes, and participants' autonomous decision making (Jariyasunant et al. 2015). Direct questions regarding the effects of fossil fuels on greenhouse effect, asked before and after the study, showed a decline in reported awareness. On potential explanation raised by the authors was the obvious 'environmentalist push' of the experiment, which may be experienced as paternalistic by participants.

\section{Outcomes and travel implications}

Outcomes of travel feedback apps reported in the literature are of different kinds. From the traveller's viewpoint, outcomes may relate to her travel behaviour. Various studies report that travellers' behaviour in response to the App changed toward increased use of environmental travel modes, and less car use (Gabrielli and Maimone 2013; Jariyasunant et al. 2015). The studies are unclear about whether participants feel that their travel has improved and become more pleasant. However, both studies report that participants in their trials were positive about using the App, found it convenient and would consider it for future use. It should be noted, though, that the studies involves small samples which are likely self-selected based on a positive attitude toward travel feedback apps. Another reported outcome is that in general, participants became more aware of the environmental and health impacts of their travel behaviour, developed more positive attitudes towards sustainable forms of travel, and increased their intention of travelling in a sustainable way in the future.

These outcomes are in line with the implicit motives of the consortia launching the apps, which are embodied in the feedback and reward mechanisms. The main concern, however, seems to lie in the low numbers of participants. If this low number is based on major objections among large parts of the travel population, the efficiency of apps as a travel behaviour change tool can be questioned. Such objections might be based on contradictions in travellers' activity systems, such as inability to change behaviour, care of privacy, fear of the hassle involved in participation or doubting the value of the outcomes envisioned by the consortium. Hence, the travel implications of travel feedback apps do not only depend on the effect observed for small pools of participants, but also on the acceptability (in a broad sense) of the tool by the general population of travellers.

\section{Conclusions and discussion}

This paper introduced activity theory (AT) as a systematic way of investigating the effect of ICTs on (amongst others) travel behaviour. The basic assumption underlying AT is that tools (such as smartphone apps) are used by subjects (in this case the traveller) to perform an activity with a certain outcome, which is driven by motives that satisfy underlying needs. We propose AT as an alternate way of analysing the effect of ICTs on travel, which has as an important merit that it analyses in detail the practises of using a specific ICT device/tool, in relation to the user's motives and embedded in a social context. Such a detailed analysis is considered a useful addition to the state of the art in research on ICTs 
and travel, which has often implicitly tended to treat ICT as a single, homogenous phenomenon, instead of recognizing the variety in ICT devices and tools, which has in recent years increased exponentially through the development of smartphone apps. In addition, studies of travel and ICTs have mostly focused on the quantitative effects of ICTs on travel, expressed in terms of substitution, complementarity, modification or neutrality, without focusing on the underlying mechanisms of such effects, the implications for both travel and other outcomes, and the embeddedness of travel and ICT use in people's daily activities and social context (the latter of which may extend to the society as a whole). Hence, we agree with Schwanen (2015) that when studying the effect of apps, more attention is needed for the functioning of apps as more or less independent agents in networks of users, stakeholders and other (ICT) devices. AT offers a framework for carrying out such analyses, with an emphasis on the relationship between user and tool, embedded in a social context.

Exploratory analyses applying AT to specific apps (WhatsApp and Travel feedback apps) based on existing literature suggest that AT may be a useful tool for analysing apps (and ICTs in general) in a broader context. Relevant issues that came to the fore include the often polymotivational nature of using apps, implying that the travel related effect of apps partly depends on non-travel related motivations, such as financial or material gain or maintaining friendships. Another important implication of the analyses is that social structure differs strongly between apps. Whatsapp is used in an egalitarian community, with users facing and similar opportunities and constraints, and have more or less likeminded motivations. On the other hand, the community around travel feedback apps includes travellers as well as the consortium launching the travel feedback programme, which have different motives for using the App, which not necessarily coincide. Our AT based analysis also gave indications of contradictions in the AS of travel related apps. For instance, difference in motives of users and program consortia may lead to counter effective stimuli that make the App less attractive for users, and withhold non-users from adopting it. Finally, AT may offer a framework to understand the development in the practises of using tools as the outcome of contradictions, such as the strategies applied by some users to handle unwelcome incoming messages.

The reliance on existing studies in this analysis has been an obvious limitation. A particular disadvantage is that scientific literature may lag behind daily practice in a rapidly changing context such as smartphone apps. For instance, while the literature regarding Whatsapp focuses on the use of this App by groups of friends of younger age, which typically were early adopters of Whatsapp, our own observations and discussions with fellow researchers suggest that the use of this App is now much more widespread, and is used to coordinate family life, social ties and club and professional activities of many. Another limitation is the focus on dedicated travel feedback apps, thereby ignoring health apps that may also provide feedback on travel behaviour (e.g. Strava). As certain health apps are more widespread than dedicated travel feedback apps, and may be used with different motivations, it is important to address their use and effects in future research.

Based on this exploration, we feel that studies based on AT can be a useful complement to survey based quantitative studies of ICTs and travel. While in survey based studies, rather straightforward assumptions need to be made about the impact of ICTs on travel, AT allows one to investigate the relationships between actors in social networks who use ICTs/ apps in much more detail and with more theoretical rigour. Importantly, studies based on AT can identify actors' practices when using ICTs/apps and increase understanding of how the effects of ICT use on travel are dependent on more general objectives of using ICTs and how these are embedded in daily practices. 
Studies of apps based on AT would typically be qualitative in nature, questioning subjects in activity systems about their motives and practices when using the App, the rules applying to the use of the App, the involved community and contradictions occurring in the activity system. Given the importance of apps as independent agents, research based on AT should also focus on the App, its linkages with other agents (either software, databases or humans), and the interaction (exchange of messages and information) with these agents. To address the relationship with travel and activities, such an approach may be complemented with more traditional approaches such as activity and travel diaries and diaries of App use.

In practice, studies based on AT could for instance be used to identify useful classifications of ICTs/apps, based on the objectives, practices and embeddedness in community, which could provide a basis for quantitative studies and may refine the taxonomy presented in this paper. In addition, studies based on AT could be used to identify differences in practices in the use of ICTs/apps, which might be related to differences in preferences, lifestyle or socio-economic position. Such findings may provide a basis for segmentation analyses in quantitative studies. Another implication of such an approach could be the identification of inequalities in the use of apps and the extent to which people have access to them and profit from them, which is indicative of equity issues. In the context of the relationship between social networks and travel, which has been an emerging area over the past decades, studies of ICTs/apps based on AT can provide important insights into the role of ICTs in maintaining social relationships and how travel and activities emerge in the context of social relationships.

Open Access This article is distributed under the terms of the Creative Commons Attribution 4.0 International License (http://creativecommons.org/licenses/by/4.0/), which permits unrestricted use, distribution, and reproduction in any medium, provided you give appropriate credit to the original author(s) and the source, provide a link to the Creative Commons license, and indicate if changes were made.

Author's contribution D. Ettema: Literature search and review, developing of conceptual models and analysis, writing and editing article.

\section{References}

Ben-Elia, E., Ettema, D.: Carrots versus sticks: rewarding commuters for avoiding the rush-hour-a study of willingness to participate. Transp. Policy 16(2), 68-76 (2009)

Ben-Elia, E., Ettema, D.: Rewarding rush-hour avoidance: a study of commuters' travel behavior. Transp. Res. Part A Policy Pract. 45(7), 567-582 (2011)

Bissell, D.: Passenger mobilities: affective atmospheres and the sociality of public transport. Environ. Plan. D Soc. Space 28(2), 270-289 (2010)

Brazil, W., Caulfield, B., Rieser-Schüssler, N.: Understanding carbon: making emissions information relevant. Transp. Res. Part D Transp. Environ. 19, 28-33 (2013)

Broll, G., Cao, H., Ebben, P., Holleis, P., Jacobs, K., Koolwaaij, J., Souville, B.: Tripzoom: an app to improve your mobility behavior. In: Proceedings of the 11th International Conference on Mobile and Ubiquitous Multimedia, p. 57. ACM (2012, December)

Carrasco, J.A., Miller, E.J.: The social dimension in action: a multilevel, personal networks model of social activity frequency between individuals. Transp. Res. Part A Policy Pract. 43(1), 90-104 (2009)

Carvalho, M. B., Bellotti, F., Berta, R., De Gloria, A., Sedano, C. I., Hauge, J. B., Rauterberg, M.: An activity theory-based model for serious games analysis and conceptual design. Comput. Education 87, 166-181 (2015).

Church, K., de Oliveira, R.: What's up with whatsapp? Comparing mobile instant messaging behaviors with traditional SMS. In: Proceedings of the 15th international conference on human-computer interaction with mobile devices and services, pp. 352-361. ACM (2013, August)

Engeström, Y.: Learning by Expanding. Cambridge University Press, Cambridge (2014) 
Engeström, Y.: Innovative learning in work teams: analyzing cycles of knowledge creation in practice. In: Engeström, Y., Miettinen, R., Punamaki, R.-L. (eds.) Perspectives on activity theory, pp. 377-404. Cambridge University Press, Cambridge (1999)

Ettema, D., Friman, M., Gärling, T., Olsson, L.E., Fujii, S.: How in-vehicle activities affect work commuters' satisfaction with public transport. J. Transp. Geogr. 24, 215-222 (2012)

Farag, S., Dijst, M., Lanzendorf, M.: Exploring the use of e-shopping and its impact on personal travel behavior in the Netherlands. Transp. Res. Rec. J. Transp. Res. Board 1858, 47-54 (2003)

Fjeld, M., Lauche, K., Bichsel, M., Voorhorst, F., Krueger, H., Rauterberg, M.: Physical and virtual tools: activity theory applied to the design of groupware. Comput. Support. Coop. Work (CSCW) 11(1-2), 153-180 (2002)

Fujii, S., Taniguchi, A.: Determinants of the effectiveness of travel feedback programs-a review of communicative mobility management measures for changing travel behaviour in Japan. Transp. Policy 13(5), 339-348 (2006)

Gabrielli, S., Maimone, R.: Are change strategies affecting users' transportation choices? In: Proceedings of the Biannual Conference of the Italian Chapter of SIGCHI, p. 9. ACM (2013, September)

Hasan, H., Kazlauskas, A.: Activity theory: who is doing what, why and how. In: Hasan, H. (eds.) Being practical with theory: a window into business research, pp. 9-14. THEORI, Wollongong, Australia (2014)

Jariyasunant, J., Abou-Zeid, M., Carrel, A., Ekambaram, V., Gaker, D., Sengupta, R., Walker, J.L.: Quantified traveler: travel feedback meets the cloud to change behavior. J. Intell. Transp. Syst. 19(2), 109-124 (2015)

Kaptelinin, V., Nardi, B.A.: Acting with Technology: Activity Theory and Interaction Design. MIT Press, Cambridge (2006)

Kwan, M.P.: Mobile communications, social networks, and urban travel: hypertext as a new metaphor for conceptualizing spatial interaction $*$. Prof. Geogr. 59(4), 434-446 (2007)

Licoppe, C., Smoreda, Z.: Rhythms and ties: towards a pragmatics of technologically-mediated sociability. In: Kraut, R., Brynin, M., Kiesler, S. (eds.) Computers, phones, and the internet: domesticating information technology, pp. 296-324 Oxford University Press (2006)

Lim, C.P., Hang, D.: An activity theory approach to research of ICT integration in Singapore schools. Comput. Educ. 41(1), 49-63 (2003)

Lyons, G.: Viewpoint: transport's digital age transition. J. Transp. Land Use 8(2), 1-19 (2014)

Lyons, G., Jain, J., Susilo, Y., Atkins, S.: Comparing rail passengers' travel time use in Great Britain between 2004 and 2010. Mobilities 8(4), 560-579 (2013)

Meloni, I., di Teulada, B.S.: I-pet individual persuasive eco-travel technology: a tool for VTBC program implementation. Transp. Res. Procedia 11, 422-433 (2015)

Mokhtarian, P.L.: Telecommunications and travel: the case for complementarity. J. Ind. Ecol. 6(2), 43-57 (2002)

Mokhtarian, P.: If telecommunication is such a good substitute for travel, why does congestion continue to get worse? Transp. Lett. 1(1), 1-17 (2009)

Mokhtarian, P.L., Tal, G.: Impacts of ICT on travel behavior: a tapestry of relationships. In: The Sage Handbook of Transport Studies, pp. 241-260 (2013)

Mokhtarian, P.L., Salomon, I., Redmond, L.S.: Understanding the demand for travel: it's not purely'derived'. Innov. Eur. J. Soc. Sci. Res. 14(4), 355-380 (2001)

Nardi, B.A.: Studying context: a comparison of activity theory, situated action models, and distributed cognition. In: Context and Consciousness: Activity Theory and Human-Computer Interaction, pp. 69-102 (1996a)

Nardi, B.A.: Activity theory and human-computer interaction. In: Context and Consciousness: Activity Theory and Human-Computer Interaction, pp. 7-16 (1996b)

O'Hara, K.P., Massimi, M., Harper, R., Rubens, S., Morris, J.: Everyday dwelling with WhatsApp. In: Proceedings of the 17th ACM Conference on Computer Supported Cooperative Work \& Social Computing, pp. 1131-1143. ACM (2014, February)

Peña-Ayala, A., Sossa, H., Méndez, I.: Activity theory as a framework for building adaptive e-learning systems: a case to provide empirical evidence. Comput. Hum. Behav. 30, 131-145 (2014)

Richter, J., Friman, M., Gärling, T.: Soft transport policy measures: gaps in knowledge. Int. J. Sustain. Transp. 5(4), 199-215 (2011)

Salomon, I.: Technological change and social forecasting: the case of telecommuting as a travel substitute. Transp. Res. Part C Emerg. Technol. 6(1), 17-45 (1998)

Schwanen, T.: Beyond instrument: smartphone app and sustainable mobility. EJTIR 15(4), 675-690 (2015) Vygotsky, L.S.: Mind in Society: The Development of Higher Mental Process. Harvard University Press, Massachusetts, Cambridge (1978) 
Wang, D., Law, F.Y.T.: Impacts of information and communication technologies (ICT) on time use and travel behavior: a structural equations analysis. Transportation 34(4), 513-527 (2007)

Wang, D., Park, S., Fesenmaier, D.R.: The role of smartphones in mediating the touristic experience. J. Travel Res. 51(4), 371-387 (2012)

Wells, S., Kotkanen, H., Schlafli, M., Gabrielli, S., Masthoff, J., Jylhä, A., Forbes, P.: Towards an applied gamification model for tracking, managing, \& encouraging sustainable travel behaviours. ICST Trans. Ambient Syst. 1(4), e2 (2014)

Zhang, F., Clifton, K.J., Shen, Q.: Reexamining ICT impact on travel using the 2001 NHTS data for Baltimore Metropolitan Area. In: Miller, H.J. (ed.) Societies and Cities in the Age of Instant Access, pp. 153-166. Springer, Netherlands (2007)

Dick Ettema is associated professor in Utrecht University and has published over 100 peer reviewed articles and various books on the interaction between land use and travel, the impact of ICTs on travel, health and well-being effects of travel and strategies to promote active travel. 